\title{
Finite Element Dynamic Analysis on Residual Stress Distribution of Titanium Alloy and Titanium Matrix Composite after Shot Peening Treatment
}

\author{
Lechun Xie, Zhou Wang, Chengxi Wang, Yan Wen, \\ Liqiang Wang, Chuanhai Jiang, Weijie Lu, \\ Lai-Chang Zhang and Lin Hua
}

Additional information is available at the end of the chapter

http://dx.doi.org/10.5772/intechopen.73120

\begin{abstract}
The residual stress distribution introduced by shot peening (SP) in the deformed surface layer of Ti-6Al-4V and (TiB+TiC)/Ti-6Al-4V were simulated and studied via the threedimensional (3D) finite element dynamic analysis and the experimental validation. The program of ANSYS/LS-DYNA was utilized, and the 3D homogeneous and inhomogeneous models were set up. The homogeneous model was established for simulating SP process on Ti-6Al-4V. The influence of three important parameters, the shot balls' size, shot velocity and coverage rate on residual stress distribution were investigated. Numerical simulation results showed that these parameters contributed different effects on SP treatment. Using a simplified method, an inhomogeneous model for simulating SP process on $(\mathrm{TiB}+\mathrm{TiC}) / \mathrm{Ti}-6 \mathrm{Al}-4 \mathrm{~V}$ was set up. The max tensile and compressive residual stress (CRS) was +1155 and $-1511 \mathrm{MPa}$, respectively. Based on this stress distribution, the beneficial effect of reinforcements was indicated during deformation, retarding the damage to the matrix and keeping the adverse tensile stresses in the reinforcements. In order to verify the results of simulation, the residual stress distribution along depth was measured by X-ray diffraction (XRD) method. The residual stress distribution by experiments was agreed with the simulated results, which verified the availability of 3D finite element dynamic analysis.
\end{abstract}

Keywords: finite element dynamic analysis, residual stress, shot peening, titanium matrix composite, reinforcement, $\mathrm{X}$-ray diffraction 


\section{Introduction}

Shot peening (SP) is an effective surface strengthening method and widely used in industry, which can effectively improve the surface performance of material. The effect of SP depends on the material and parameters during SP process. The small SP intensity will lead to the strengthening effect unobvious, but the excessive SP intensity may result in the formation of micro-cracks and reduce the strength. So, a proper SP intensity should be conducted. Additionally, the improper shot balls will increase the surface roughness of material, which is not benefit to the surface properties. During SP, the shot balls impact the surface of material at a high speed, which transforms the kinetic energy of shot balls into the elastic energy of internal stress. So after SP, the internal energy of material is increased, and it is in the metastable state. While the external environment changes, the material with high energy may be transferred to the low energy state spontaneously, leading to the stress relaxation. For instance, in the high temperature environment, the residual stress will promote the local creep of the material, resulting in reducing the residual stress, which will weaken the effect of SP and be not conducive to the improvement of fatigue properties [1].

Usually, the fatigue strength and fatigue life of cyclically loaded metallic components can be considerably improved due to the compressive residual stress (CRS) and work hardening induced on the surface layer after SP [2]. The distribution of CRS is mainly affected by the parameters of SP and the materials' condition. A significant number of parameters are needed to be regulated and controlled in order to obtain a more beneficial CRS distribution. Therefore, in practical application of SP, the empirical knowledge should be accumulated for getting the appropriate processing parameters, which usually requires time and money consuming. For obtaining the suitable SP parameters and minimizing these trails, the numerical simulation of SP is conducted, building a better understanding of SP process with the aim of study, analyzing and predicting the relationship between the influencing factors and simulation results.

SP simulation has been developed since more than four decades. Some references have indicated that finite element method is a suitable and useful method to predict residual stress distribution after SP [3-7]. The finite element models for SP include 2D and 3D models. Usually, 2D models are adopted to simulate a single impact on a semi-infinite target body, and the simulated accuracy is verified by comparing the simulated stress distribution with the results measured by neutron diffraction and X-ray diffraction (XRD) methods. [8-12]. However, based on the direct comparison of residual stress distribution along the symmetry axis of a $2 \mathrm{D}$ model with the experimental results, it is questionable because the measurement area by experiment is different from the impact area of 2D simulation. Generally, the measurement area by some techniques, like XRD, neutron diffraction, and hole drilling, is larger than the diameter of dimple utilized in 2D models, and these techniques just provide macroscopic stress values. Moreover, a very important parameter, the coverage rate, cannot be considered in $2 \mathrm{D}$ simulation during the multiple SP process. The shortcomings of $2 \mathrm{D}$ 
models mentioned above lead to the introduction and popular application of 3D models. Because the 3D SP models can show the effect of SP coverage rate on residual stress distribution, they are approaching to the practical work more and become the main choice in recent years, especially 3D models with dynamic analysis. In the overview of SP simulation, some 3D models are adopted with different model descriptions, kinds of material models, kinds of analysis, number of shot balls, and so on [8, 13-20]. On these 3D models, most studies focus on homogeneous material and few work involves 3D inhomogeneous inclusions while establishing models. Even though some researchers have established 3D inhomogeneous models for metal matrix composites using other methods [21-25], few investigation focused on SP.

Composite material is composed of two or more kinds of materials with different chemical and physical properties, and also with different size such as micro or macro. In metal matrix composites, the difference in the properties of metal matrix and reinforcement makes the presence of interface. Due to the mismatch between matrix and reinforcement, the material properties in the vicinity of the interface are not continuous, so that the material properties and microstructure in the vicinity of the interface will vary obviously. The variation of properties has a serious effect on the macroscopic properties of the composites [26]. The size of reinforcement in the composite is typically between several $\mu \mathrm{m}$ and several tens of $\mu \mathrm{m}$, but the irradiation area of X-ray analysis is about $1 \mathrm{~mm}^{2}$, therefore, it is difficult to determine the stress distribution around reinforcement in the composite by experimental method. It is a feasible method to carry out numerical simulation using finite element analysis to solve this problem.

As one kind of important metal matrix composites, titanium matrix composites have wide application prospects in the field of aerospace, automobile, and other industries because of their good properties such as high specific strength, good ductility, and excellent fatigue properties, etc. [27-29]. About the residual stress distribution of titanium matrix composites after SP, the experimental investigation has been carried out in our previous work by XRD method [30-33]. However, the measured residual stress by experiments only reveals the average stress of matrix and reinforcements, because the beam size of $\mathrm{X}$-ray is much bigger than the dimension of reinforcement. So, it is hard to directly test the residual stress distribution in and around the reinforcements by experiments, which depends on the method of simulation. In our current work, 3D finite element dynamic analysis of multiple shot impacting is performed on Ti-6Al-4V alloy and titanium matrix composite $(\mathrm{TiB}+\mathrm{TiC}) / \mathrm{Ti}-6 \mathrm{Al}-4 \mathrm{~V}(\mathrm{TiB}: \mathrm{TiC}=1: 1$ (vol\%)). The program of ANSYS/LS-DYNA [34] is utilized in the 3D finite element dynamic analysis, and the 3D homogeneous and inhomogeneous models are set up. The systematic study is conducted using this 3D dynamic model to investigate the effect of coverage rate, shot balls' radius, and shot velocity on the residual stress distribution after SP. Moreover, TiC and $\mathrm{TiB}$ reinforcements in the composite are constructed in a composite method by the simplified inhomogeneous model. The influence of reinforcements on the stress distribution is analyzed, and the residual stresses in and around reinforcements are obtained and discussed in detail. Moreover, the experimental results by XRD method are compared with the simulation results finally. 


\section{Finite element simulation on homogeneous SP model}

\subsection{Homogeneous SP model}

\subsubsection{Introduction of SOLID164 element}

The explicit dynamic analysis of ANSYS/LS-DYNA program provides a rich element library, including 3D bar element (LINK160), 3D beam element (BEAM161), thin shell element (SHELL163), solid element (SOLID164), spring damping element (COMBI165), mass element (MASS166), cable element (Link167), and ten-node tetrahedral element (TetSolid168). Each explicit dynamic element has a corresponded linear displacement function, and the default is set to a single point of integration (one of the reduced integrals). It has been proved that the explicit dynamic element with linear displacement function and the element integration can be used for solving the nonlinear problems effectively, such as the cases of large deformation and material's failure [34]. The element utilized in simulation of SP is the SOLID164 element, which is a 3D explicit solid element consisting of eight nodes. Each node in SOLID164 has the degrees of freedom in $x, y, z$ direction of translation, velocity, and acceleration. The geometry, node locations, and the coordinate system for SOLID164 element are shown in Figure 1 [35]. This element is only used in the dynamic explicit analysis, which supports all licensed nonlinear characteristics. By default, SOLID164 is the single point integral with the viscous hourglass control to speed up the calculation.

In the process of explicit dynamic analysis, the processing of element integral is the most time-consumption, and the processing time by CPU is proportional to the number of integral
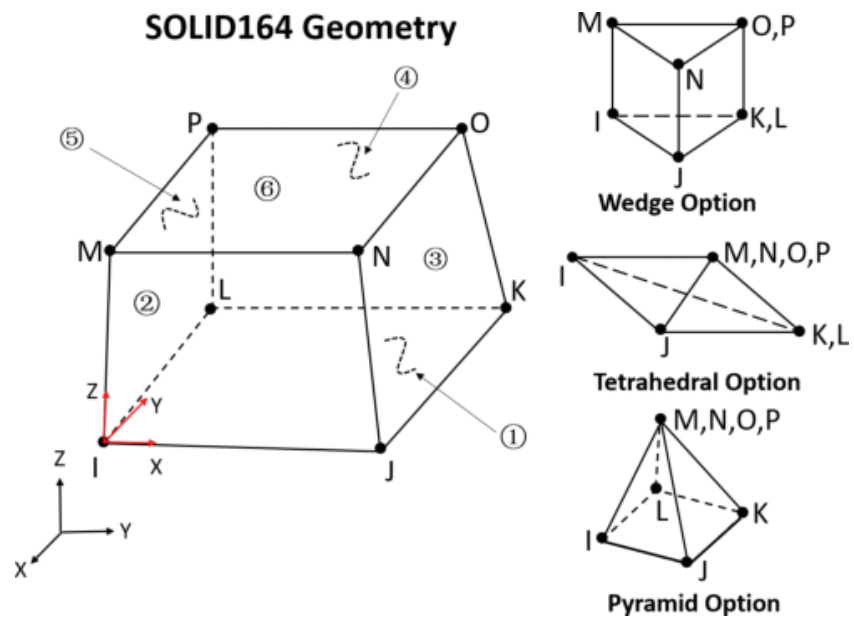

Figure 1. Geometry properties of SOLID164 [35]. 
points. So, using the simplified integration of elements can save the data storage capacity and reduce the number of calculations greatly, for instance, the single point integral in SOLID164 element, that is, an element has only one integration point, which is in the center of element. The utilization of single points can save a lot of calculation time, but may lead to the hourglass phenomenon. Mesh deformation with an hourglass effect is called the hourglass phenomenon, and in this situation, the typical feature is that the nonrigid element grid is distorted irregularly, resulting in a mathematically stable state but a physically impossible state. The presence of hourglass phenomenon will distort the results of the solution and even the solution cannot be carried out. Therefore, when using the simplified integration of elements, the hourglass phenomenon should be controlled. In ANSYS/LS-DYNA finite element analysis process, if the result of hourglass energy calculated by the model is less than $10 \%$ of the total energy, this simulation result and the model can be identified as credible.

\subsubsection{Piecewise linear plasticity model}

The choice of material model is not only related to the success of simulation, but also directly related to the rationality and reliability of calculated results. The process of SP causes a high plastic deformation in the surface layer, so Cowper-Symbols in ANSYS is adopted to achieve 3D finite element dynamic analysis [34]. Cowper-Symbols model is a piecewise linear plasticity model, and the yield stress can be obtained via the strain rate, which is shown in Eq. (1).

$$
\sigma_{y}\left(\varepsilon_{e f f}^{p}, \dot{\varepsilon}_{e f f}^{p}\right)=\sigma_{y}\left(\varepsilon_{e f f}^{p}\right)\left[1+\left(\frac{\dot{\varepsilon}_{e f f}^{p}}{C}\right)^{\frac{1}{p}}\right]
$$

$\dot{\varepsilon}$ represents the effective strain rate, $P$ and $C$ are the parameters for strain rate, and $\sigma_{y}\left(\varepsilon_{\text {eff }}^{p}\right)$ is the original yield stress while the strain rate has not been considered. In this model during simulation, the input data include totally: the density of material $\rho$, the elastic modulus of material $E$, Poisson's ratio $v$, the yield stress, the tangent modulus, the strain rate parameters $P$ and $C$, and the true stress-strain curve. If the load curve is used, the yield stress and tangent modulus are ignored. If $P$ and $C$ are set to 0 , the strain rate effect is omitted.

\subsubsection{Establishment of homogeneous SP model}

Before establishing SP model for (TiB+TiC)/Ti-6Al-4V, the 3D model for homogeneous matrix Ti-6Al-4V should be established firstly. For reducing the number of elements and the calculation time, the symmetry of SP sample and shot balls should be considered, and a 1/2 model can be set up. The 3D homogeneous model established in this work is shown in Figure 2 [36], including the top four-layer of shot balls, and the bottom of peened target. The dimension of peened target is $12 R \times 6 R \times 2.1 \mathrm{~mm}^{3}$, in which $R$ is the average radius of shot balls. Because of the intensive impacting in the near surface layer, a mesh refinement is adopted and each mesh depth is $0.02 \mathrm{~mm}$. SOLID164 dynamic analysis element is chosen for meshing element, and total mesh number is 120,000 . 


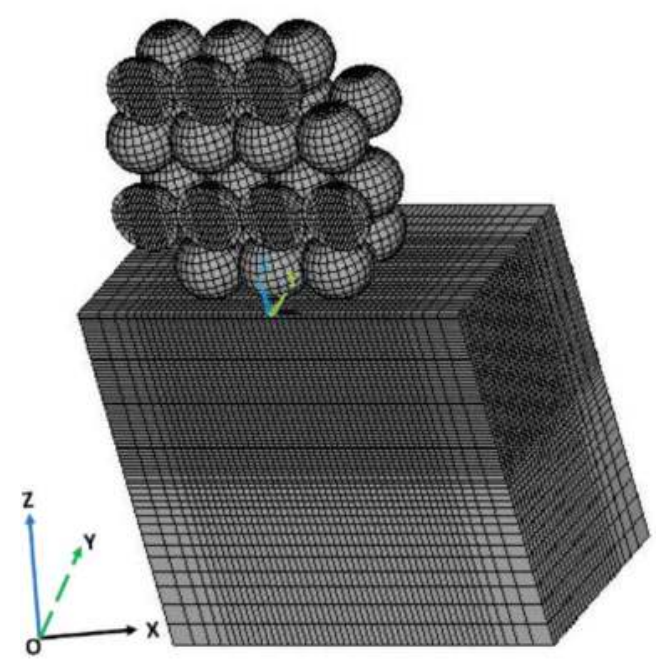

Figure 2. 3D SP model for homogeneous materials [36].

For improving the computational efficiency, the mesh size gradually increases at the model boundary and the lower half. In order to avoid the influence of reflected stress wave within the target on the distribution of residual stress during the process of impacting, nonreflective boundary conditions are implemented on the bottom and flank of the target. Because the XOZ plane is symmetrical, the symmetrical boundary conditions are applied. Because a small size model $\left(12 R \times 6 R \times 2.1 \mathrm{~mm}^{3}\right)$ may lead to the nonreal oscillation while simulating the process of impacting, in order to eliminate the effect of nonreal oscillation, the alpha damping constraint is applied to the model in the dynamic analysis. The alpha damping is a damping coefficient proportional to the mass and is very effective for the low frequency oscillations.

In 3D SP model, the top four-layers are shot balls made by case steel, and the hardness and strength of matrix is smaller than that of the case steel balls. The deformability of shot balls is very weak, which hardly affects the results of residual stress distribution. Therefore, the shot balls are defined as rigid bodies. During the explicit dynamics analysis, the degrees of freedom of all nodes in the rigid body are coupled to the mass center of rigid body, thus greatly reducing the computational time of the explicit analysis. Moreover, the corresponding mechanical parameters are given to the rigid body center to describe the dynamic characteristics. In addition, the coverage rate is very important to the distribution of residual stresses after SP. In order to keep the simulation accuracy, the coverage rate is defined and the schematic is shown in Figure 3 [36]. Four impacts with shot balls are performed in current 3D model. On a single impact, the coverage rate is about $25 \%$, and after four impacts, it approaches $100 \%$. If coverage rate increases to $200 \%$, eight impacts should be carried out in turn.

Because the piecewise linear model is adopted during simulation, the true stress-strain curve is needed. Usually, the stress-strain curve obtained by experiment is the engineering stressstrain curve, which is needed to be transformed into the true stress-strain curve, and the formula of transformation is shown in Eqs. (2) and (3). 


$$
\begin{gathered}
\sigma_{t}=\sigma_{\varepsilon}\left(1+\varepsilon_{\varepsilon}\right) \\
\varepsilon_{t}=\ln \left(1+\varepsilon_{\varepsilon}\right)
\end{gathered}
$$

$\sigma_{t}$ is the true stress, $\sigma_{\varepsilon}$ is the engineering stress, $\varepsilon_{t}$ is the true strain, and $\varepsilon_{\varepsilon}$ is the engineering strain [37]. The true stress-strain curve is used to provide the corresponding deformation parameters for the shot peened material in the finite element model. Because of the existence of reinforcements in composite and the influences of which on the matrix's residual stress distribution, the strain-stress curves with a single strain rate $\left(10^{-3} \mathrm{~s}^{-1}\right)$ are utilized during simulation. The dynamic stress-strain curves become flatter with increasing strain rate, which reduces the material strain hardening [38]. Thus, considering the variation of strain rates, based on the references $[39,40]$ and Eq. (1), the parameters $C$ and $P$ are set as $C=1300$ and $P=5$.

The true stress-strain curves of Ti-6Al-4V and (TiB+TiC)/Ti-6Al-4V can be obtained from the tensile tests. The dimension of tensile specimens with a gauge section of $4 \times 1.8 \times 18 \mathrm{~mm}$ is shown in Figure 4(a), and the axes direction is parallel to the hot-forging direction. The tensile tests are performed using a Zwick T1-FR020TN test machine in air, and the initial strain rates is $10^{-3} \mathrm{~s}^{-1}$. The true stress-strain curves are shown in Figure 4(b), which are implemented in the simulation process as the elastic-plastic deformation curves. In addition, the typical mechanical parameters of shot balls, target, and reinforcements are shown in Table 1.

\subsection{Simulated results and discussion}

\subsubsection{Residual stress distribution on surface}

In order to show the deformation of material obviously after SP, the coverage rate of $300 \%$ is chosen and the shot velocity is $100 \mathrm{~m} / \mathrm{s}$. The simulation results of $x$-direction principal stress $\left(\sigma_{x x}\right)$ are shown in Figure 5. From the Figure 5(a), it can be found that after SP, there is a compressive stress field with a certain depth in the plastic deformation area below the shot balls, and the

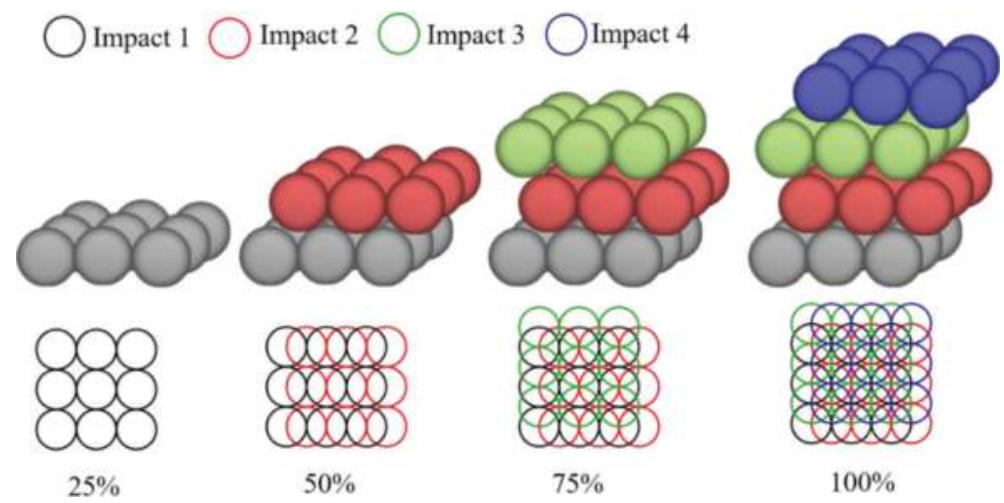

Figure 3. Coverage rate of SP with different impacts [36]. 


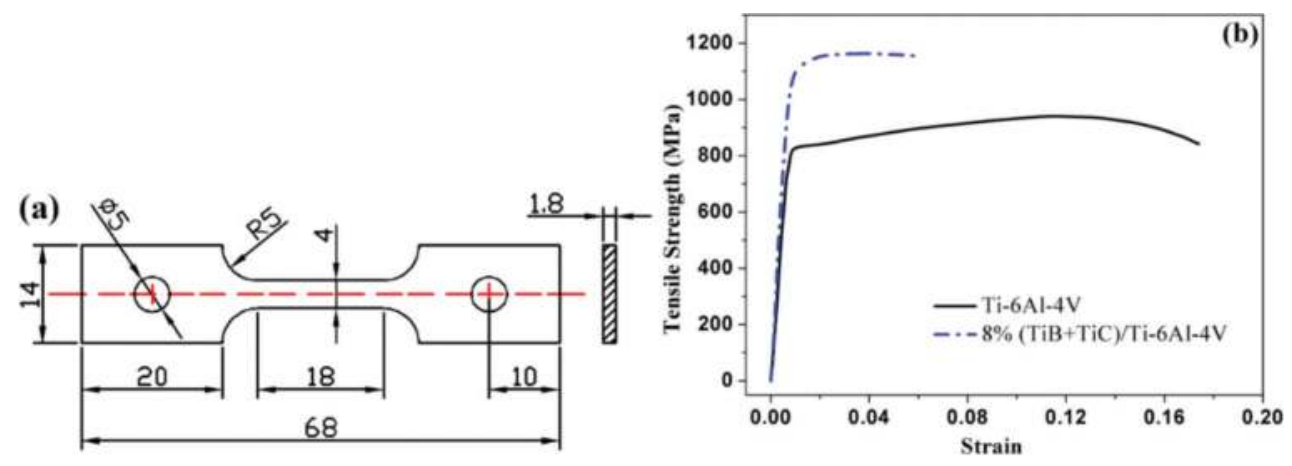

Figure 4. (a) Specimen size for room temperature tests (unit: $\mathrm{mm}$ ); (b) stress-strain curves of the matrix and composite (strain rate: $10^{-3} \mathrm{~s}^{-1}$ ).

\begin{tabular}{lllll}
\hline & Shot balls & Ti-6Al-4V & TiB & TiC \\
\hline Density $\rho\left(\mathrm{Kg}^{-3} \mathrm{~m}^{-3}\right.$ & 7800 & 4500 & 4520 & 4930 \\
Poisson's ratio $v$ & 0.30 & 0.34 & $0.14-0.15$ & $0.18-0.2$ \\
Young's modulus E (GPa) & 210 & 112 & $371-485$ & $400-460$ \\
Constraint of the part & Rigid & Elastic-plastic & Elastic-plastic & Elastic-plastic \\
\hline
\end{tabular}

Table 1. Typical mechanical parameters of shot balls and target.

distribution of CRS in the plastic deformation zone is uniform, which is about -900 to $-1000 \mathrm{MPa}$. However, in the 2D result of surface in Figure 5(b), the distribution of residual stress is not uniform, and the max CRS is about $-1453 \mathrm{MPa}$, which results from the stress concentration on the impact point of shot ball. In addition, there is tensile residual stress in some area between two craters. As the impacting time of shot ball on material's surface is different, the size of crater on the surface is not consistent, and the area of craters formed firstly is significantly reduced by the extrusion of follow-up craters. In these extruded area, the tensile residual stress is formed, but after repeated SP, the distribution of residual stress is gradually tended to uniform.

Due to the repeated impact and extrusion of shot balls, the plastic deformation appears and many craters are formed on surface. The formation of craters results in the increase of surface area and the appearance of tensile residual stress, which is also the reason that the max CRS does not appear on surface. On surface, the residual stress includes both the compressive stress formed by the plastic deformation and the tensile stress formed by the increase of surface area. With the increase of depth, the tensile residual stress decreases gradually but the CRS is gradually increased, then the max CRS is reached at a certain depth. At last, due to the reduction of plastic deformation, the CRS is gradually reduced to the level of stress before SP. In Figure 5(b), it can be found that there is tensile stress on the surface boundary. The formation of such tensile stress field is mainly due to the limitation of finite element model size (only $12 R \times 6 R$ ), and the SP area only $8 R \times 4 R$ in order to avoid the effect of model boundary 


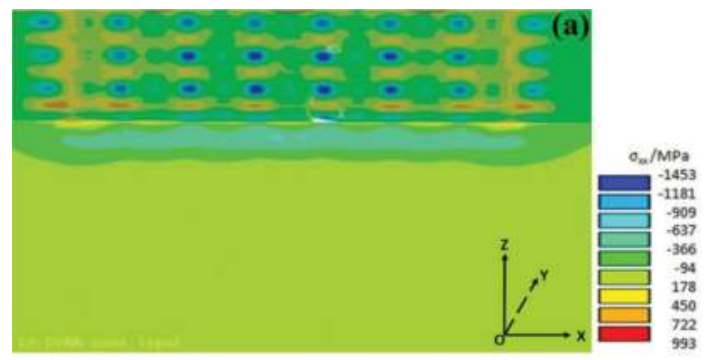

(b)

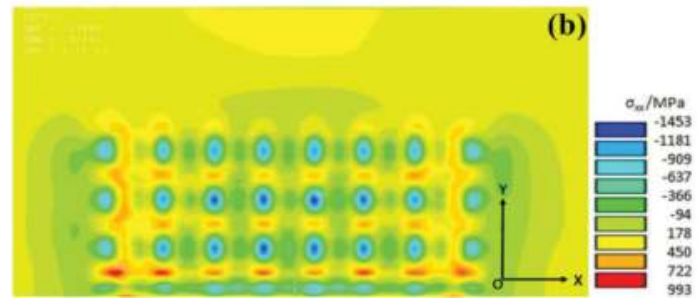

Figure 5. Simulation results of residual stress field of SP $\left(\sigma_{x x}\right)$, (a) 3D result; (b) 2D result of surface.

on the simulation results. So, the tensile stress field of surface boundary has no effect on the residual stress distribution in the plastic deformation zone. Moreover, in the actual SP experiment, the whole surface of material is subjected to SP process, and the uniform CRS can be obtained. The surface tensile stress on the boundary disappears at the same time.

The effect of SP on the residual stress distribution is mainly described by the residual stress variation with the increase of depth and the four characteristic parameters (the surface residual stress, the max residual stress, the depth of residual stress layer, and the depth of max residual stress). Usually, in experiment, after SP, the surface layer of samples are subjected to electrochemical etching and removed layer by layer (each layer is about 15-20 $\mu \mathrm{m}$ ), and then the stress value of each layer can be measured by XRD method, and the curves of residual stress variation along the depth are obtained. In order to avoid measurement error, the irradiation area of X-ray on the surface is generally about $1 \mathrm{~mm}^{2}$, so actually, the measured stress by experiment is the average stress under the statistical of surface area in $1 \mathrm{~mm}^{2}$. In this numerical simulation, for obtaining the distribution of residual stress along the depth, the stress value of all nodes at a certain depth along $\mathrm{Z}$ direction are selected and averaged, which can represent the average stress in a certain depth. Using this method to average the stress values of all nodes, the curve of residual stress distribution with the increase of depth can be obtained.

\subsubsection{Influence of coverage rate on residual stress distribution}

After SP, the surface coverage rate refers to the ratio of the area occupied by the shot craters to the area of surface required for SP. During the process of SP, the coverage rate is usually required for reaching or exceeding $100 \%$. Moreover, in the experiment, the coverage rate more than $100 \%$ can be expressed as a multiple of the time required for a full coverage rate of $100 \%$, for example, the coverage rate of $200 \%$ means that the SP time is two times of full coverage. 
In order to simplify the model, the collision between two shot balls are not considered, and SP position of each ball can be precisely controlled. Therefore, the different coverage rate can be simulated by the multi-layer shot balls and the coverage increases linearity with the number of layers. In this work, the characteristics of 100\% coverage rate (4-layer shot balls), $200 \%$ coverage rate (8-layer shot balls), and 300\% coverage rate (12-layer shot balls) are simulated. The shot velocity are set as 50 and $100 \mathrm{~m} / \mathrm{s}$ based on experiment (mentioned in Section 2.2.4), and the average radius of shot balls are chosen as $0.15,0.3$, and $0.6 \mathrm{~mm}$. The influence of coverage rate, radius of shot balls $(r)$, and shot velocity $(v)$ on residual stress distribution are investigated and discussed.

Figure 6 shows the distribution of residual stress along depth with different coverage rates. While the radius and speed of shot balls are constant, the similar variation trend of residual stress can be obtained. With the increase of coverage rate, the CRS and the depth of stress layer are improved. In addition, the depth of max CRS decreases with the increase of coverage rate, which is more obvious in Figure 6(e) and (f). Comparing the results under coverage rate of 200 and $300 \%$, it can be found that the increment of surface residual stresses are not obvious with increasing the coverage rate, since the surface of almost all area is covered by craters and the stress field reaches saturation. Though there is a little bit increment of the max CRS while coverage rate increases from 200 to $300 \%$, there is not obvious comparing the coverage variation from 100 to $200 \%$.

The simulated pictures about residual stress distribution under different coverage rates are shown in Figure 7, while $r=0.3 \mathrm{~mm}$ and $v=100 \mathrm{~m} / \mathrm{s}$. With increasing coverage, the number of craters on surface increases, and the surface residual stresses becomes more uniform. As well, the uniformity of residual stress distribution on subsurface is also improved while viewed from the cross section, and slight tensile stresses in the deep surface decrease gradually and disappear with the increase of coverage rate.

\subsubsection{Influence of shot balls' radius on residual stress distribution}

According to the formula of $m=\frac{4}{3} \pi \rho R^{3}$, the mass of shot ball is not only linearly related to the density, but also is proportional to $R^{3}$. In most of the industrial production, the criterion for choosing the size of shot ball is based on the surface roughness after SP. If it requires high quality of surface (small roughness), the small radius of shot ball is chosen. If there is no high quality requirement of surface, the big radius of shot ball is determined, because the cost of shot balls with small radius are much higher than that of big shot balls. Besides the influence of shot ball's radius on surface roughness, the shot ball also influences the residual stress distribution. So the influence of three kinds of different radius $(r=0.15,0.3$, and $0.6 \mathrm{~mm})$ on the residual stress distribution of $\mathrm{Ti}-6 \mathrm{Al}-4 \mathrm{~V}$ is simulated by the model, while the shot velocity is $100 \mathrm{~m} / \mathrm{s}$. The results of the residual stress versus depth are shown in Figure 8. From the simulation results, it can be found that the surface CRS and max CRS are higher while using small shot balls, but the layer depth of CRS is smaller and the CRS decreases rapidly with increasing depth. When using the big shot balls, both the surface and max CRS are smaller, however, the layer depth of CRS is deeper and CRS decreases slowly with increasing depth.

Some work have shown that when the coverage rate is $100 \%$, the depth of CRS layer has the following relationship with the crater diameter and the shot ball's diameter. 

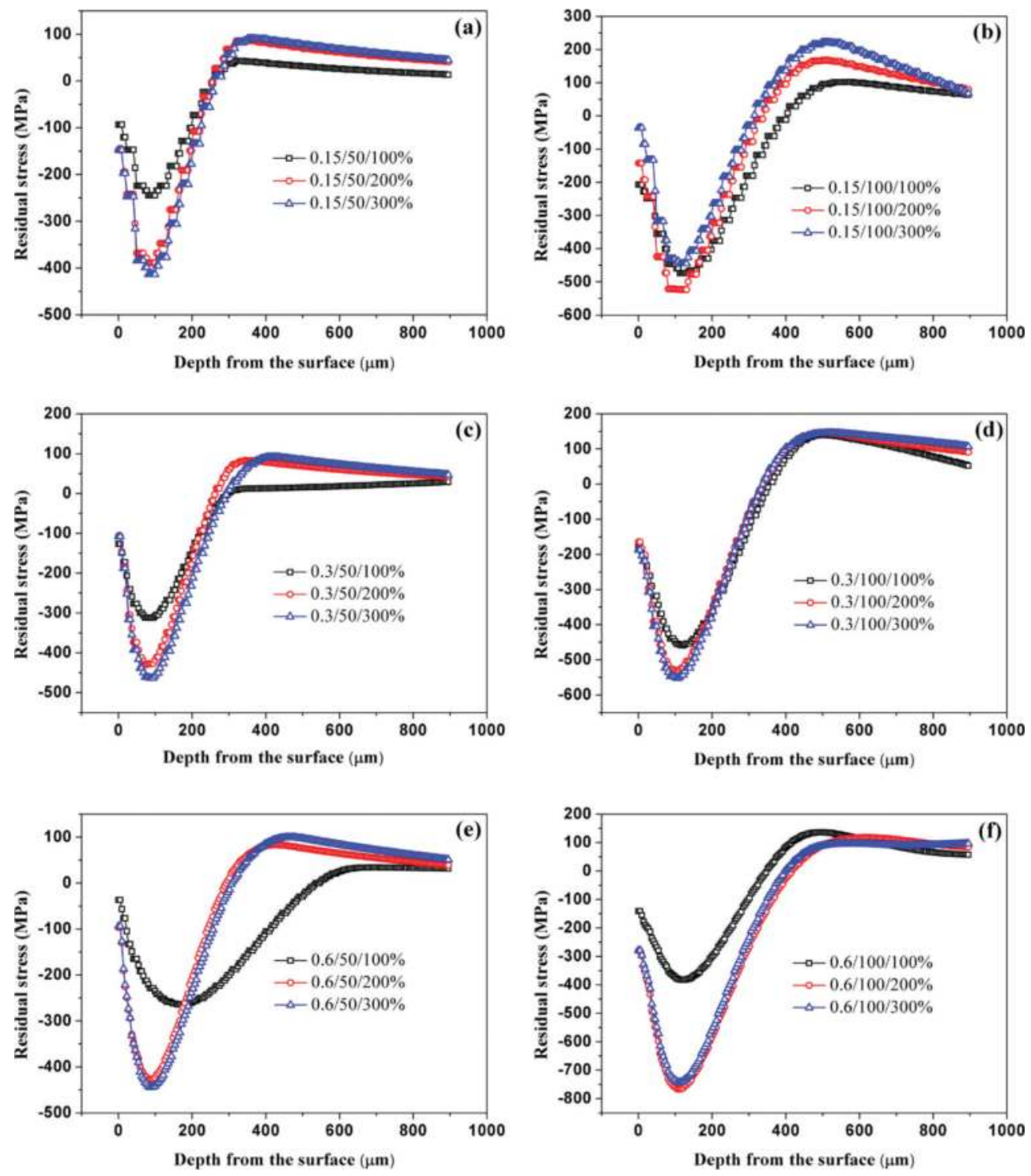

Figure 6. Residual stress distribution in depth with different coverage rates, (a) $r=0.15 \mathrm{~mm}, v=50 \mathrm{~m} / \mathrm{s}$; (b) $r=0.15 \mathrm{~mm}$, $v=100 \mathrm{~m} / \mathrm{s}$; (c) $r=0.3 \mathrm{~mm}, v=50 \mathrm{~m} / \mathrm{s}$; (d) $r=0.3 \mathrm{~mm}, v=100 \mathrm{~m} / \mathrm{s}$; (e) $r=0.6 \mathrm{~mm}, v=50 \mathrm{~m} / \mathrm{s}$; (f) $r=0.6 \mathrm{~mm}, v=100 \mathrm{~m} / \mathrm{s}$.

$$
Z_{0}=a \times D-c \times R
$$

$D$ is the crater diameter, $Z_{0}$ is the depth of CRS layer, $\mathrm{R}$ is the shot ball's diameter, and $a, c$ are constant coefficients. In general, the value of $a$ is between 1 and 1.5, and the value of $c$ is in 

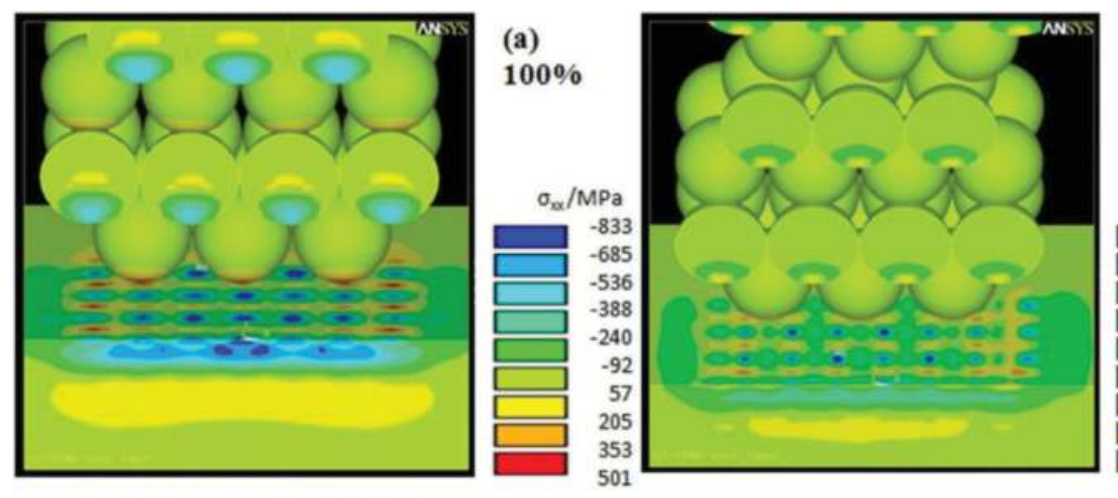

(b) $200 \%$

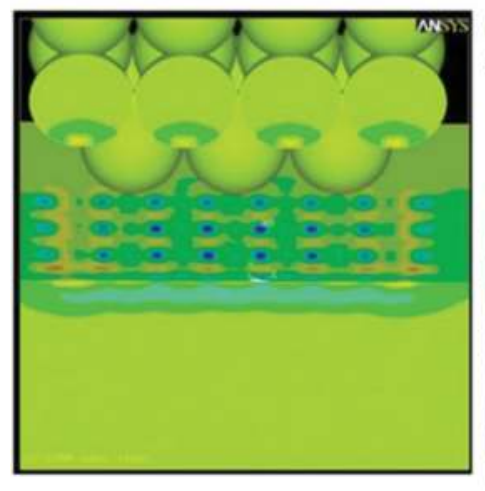

(c)

$300 \%$

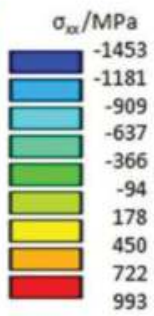

Figure 7. Residual stress distribution after SP with different coverage rates: (a) $100 \%$; (b) $200 \%$; (c) $300 \%$. [36].

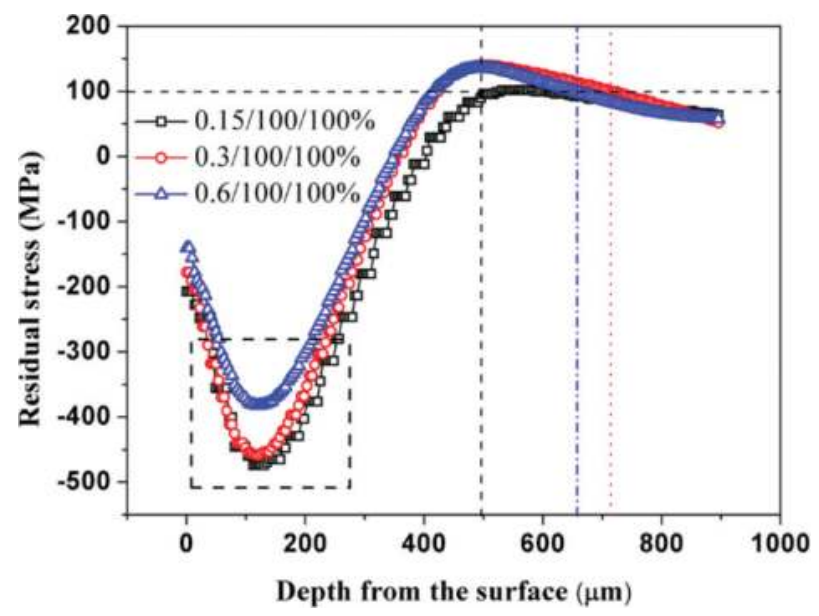

Figure 8. Influence of shot radius on depth distribution of residual stress $(v=100 \mathrm{~m} / \mathrm{s}$ and coverage $=100 \%)$. 
the range from 0 to 0.1 . In order to obtain the values of $a$ and $c$, the SP experiment should be carried out. Firstly, the same material as the workpiece is chosen and then the surface of this material is subjected to SP treatment. Secondly, the diameter of crater and the depth of CRS are measured. And at last, the values of $a$ and $c$ are calculated by linear fitting. Based on the values of $a$ and $c$, the depth of CRS layer can be estimated. At the same shot velocity, the diameter of crater increases with increasing shot diameter, and thus the depth of CRS layer increases.

\subsubsection{Influence of shot velocity on residual stress distribution}

SP is the process of consuming shot balls' kinetic energy and transfer the kinetic energy to the deformation energy of target material. So, after SP, the elastic and plastic deformations are introduced in the surface layer of target material. The shot balls' mass and velocity directly affect the value of kinetic energy. When the material of shot balls is same, the kinetic energy increases with the improvement of shot velocity. In SP experiment by using an air blast machine, the shot velocity can be varied and obtained by adjusting the air pressure. During the flight of shot balls, the velocity will be decreased because of the collision between them and the effect of air resistance, and the attenuation is related to the distance between the nozzle and the material. The smaller diameter of shot ball, the velocity attenuation is more obvious. The attenuation rates of cast shot balls $\left(\rho=7.8 \mathrm{~g} / \mathrm{cm}^{3}\right)$ with different diameters at different shot distances are shown in Figure 9 [41]. From this figure, it can be found that when the shot distance is less than $2 \mathrm{~m}$, the attenuation rates are proportional to the distance increment.

The shot velocity is also affected by the shot angle in addition to the attenuation with the distance. When the shot balls impact on the surface of workpiece at a certain angle, the velocity can be decomposed into two directions. One is perpendicular to the surface (normal velocity) and the other is parallel to the surface (tangential velocity). The former velocity contributes to the plastic deformation of the surface layer, but the latter only promotes the friction effect. Based on the above analysis, in the experiment of this work, the distance between nozzle and samples is $100 \mathrm{~mm}(0.1 \mathrm{~m})$,

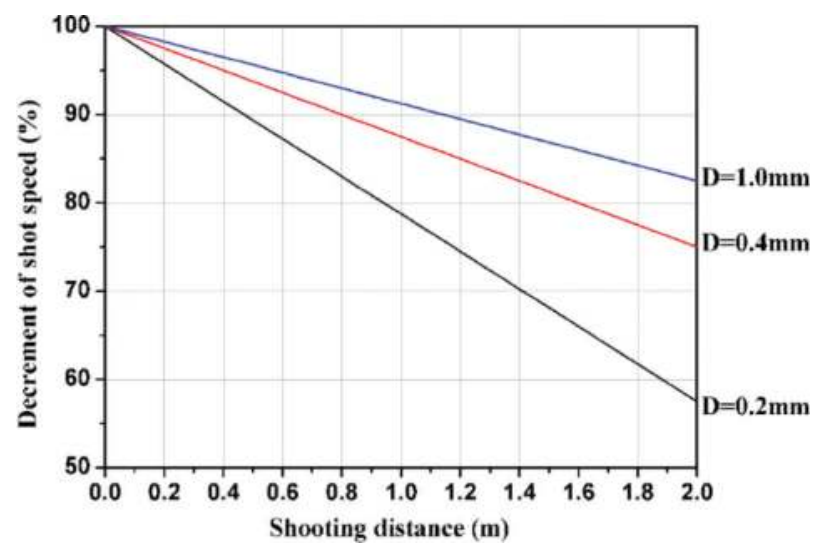

Figure 9. Relationship between decrement of shot velocity and shooting distance [41]. 

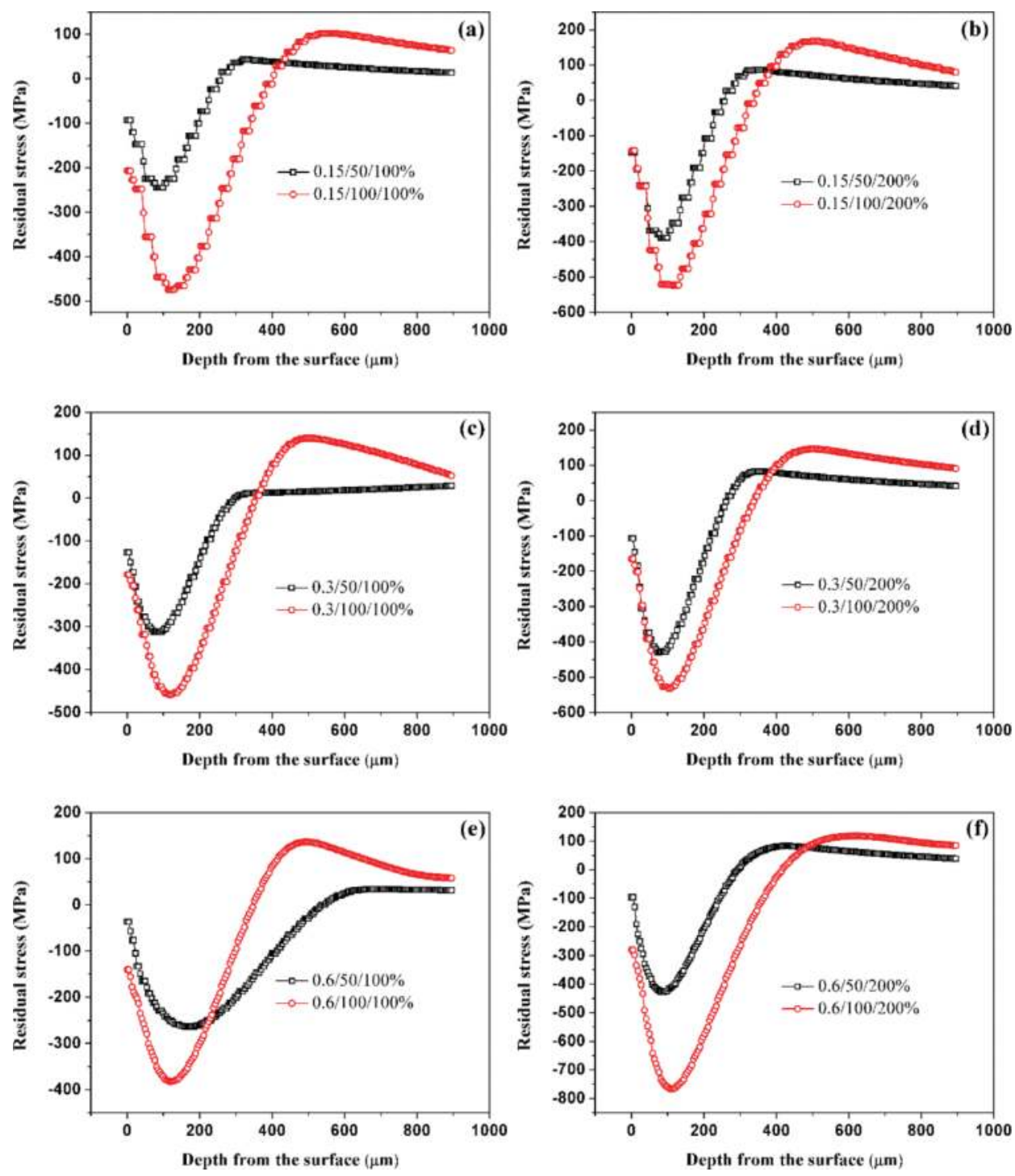

Figure 10. Residual stress distribution in depth with different shot velocities, (a) $r=0.15 \mathrm{~mm}$, coverage $=100 \%$; (b) $r=0.15 \mathrm{~mm}$, coverage $=200 \%$; (c) $r=0.3 \mathrm{~mm}$, coverage $=100 \%$; (d) $r=0.3 \mathrm{~mm}$, coverage $=200 \%$; (e) $r=0.6 \mathrm{~mm}$, coverage $=100 \%$; (f) $r=0.6 \mathrm{~mm}$, coverage $=200 \%$.

in which, the shot velocity on surface is almost the same as initial velocity. Moreover, the direction of peening nozzle is perpendicular to the surface, which can keep the shot velocity perpendicular to the surface and transfer most of kinetic energy to the deformation energy.

In order to simulate the practical process of SP better, the actual shot velocity is estimated by the semi-experiential formula introduced by Dr. Klemenz [42], which is shown in Eq. (5). 


$$
v=\frac{16.35 \times p}{1.53 \times m+p}+\frac{29.50 \times p}{0.598 \times d+p}+4.83 \times p
$$

$m, p$, and $d$ represent the flux of shot balls $(\mathrm{kg} / \mathrm{min})$, the jet pressure (bar), and the diameter of shot balls (mm), respectively. In current experiment, the value of $m$ is $0.5 \mathrm{~kg} / \mathrm{min}$. The different SP parameters are shown: (1) $0.15 \mathrm{mmA}$ (SP intensity), 4 bar (air pressure), $0.5 \mathrm{~min}$ (SP time); (2) $0.3 \mathrm{mmA}, 10 \mathrm{bar}, 0.5 \mathrm{~min}$. The average radius of shot balls $r=0.3 \mathrm{~mm}$. Based on above parameters, the approximate shot velocities are estimated as 57 and $92 \mathrm{~m} / \mathrm{s}$, corresponding to SP intensities of 0.15 and $0.3 \mathrm{mmA}$ respectively. Thus, the shot velocities of 50 and $100 \mathrm{~m} / \mathrm{s}$ are considered in this work.

During simulation, the initial shot velocity represents SP intensity. The larger velocity means the higher SP intensity. Figure 10 indicates the residual stress distribution in depth with different initial velocities. In these figures, the variation trends are similar. While increasing velocity, both the surface and max CRS significantly increase and the depth of deformation layer is also improved. At $v=100 \mathrm{~m} / \mathrm{s}$, the max depth of CRS in the material reaches $600 \mu \mathrm{m}$ with $r=0.6 \mathrm{~mm}$ and coverage $=200 \%$ (in Figure 10(f)). The surface residual stress is less affected by the shot velocity while $r=0.3$ and the surface residual stress is around -100 to -200 MPa (in Figure 10(c) and (d)). Because one part of the kinetic energy is transferred to the deformation energy during SP, while increasing shot velocity, much more kinetic energy can be transferred to the deformation energy, which can result in the surface deformation more severely and the deeper deformation layer can be obtained.

\section{Finite element simulation on inhomogeneous SP model}

\subsection{Establishment of inhomogeneous SP model}

In order to set up 3D SP model for inhomogeneous materials, the morphology of reinforcements were observed by scanning electron microscope (SEM, Hitachi S-3400 N, Japan) under $15 \mathrm{kV}, 70 \mu \mathrm{A}$. Before SEM observation, the samples were ground by abrasive papers, and then by the diamond papers and the aluminum oxide suspensions in order. For acquiring clear morphology of reinforcements, the sample was etched using Kroll's solution (HF: $\mathrm{HNO}_{3}$ : $\mathrm{H}_{2} \mathrm{O}=3: 5: 100(\mathrm{vol})$ ) for 2-6 s after polishing. All experiments were performed at room temperature. The SEM images of reinforcements in (TiB+TiC)/Ti-Al-4V after etching on surface with different percentage have been shown in Figure 11 [36, 43]. It is indicated that the reinforcements are distributed uniformly in the composite. The reinforcements like short sticks are $\mathrm{TiB}$, while the equiaxed or near equiaxed particles are TiC. In the following work, the 3D SP model for inhomogeneous materials is based on the microstructure of reinforcements in $8 \%$ (TiB+TiC)/Ti-6Al-4V. Based on the simulated results from homogeneous model, the inhomogeneous SP model containing the reinforcements is built in this part and the residual stress distribution in and around the reinforcements are obtained and analyzed. In this model, the parameters of $v=100 \mathrm{~m} / \mathrm{s}, r=0.3 \mathrm{~mm}$ and coverage $=200 \%$ are chosen as the initial parameters.

The 3D SP model for inhomogeneous materials is shown in Figure 12 [36] based on the microstructure observation of reinforcements. In the figure, the green part represents the matrix, the 


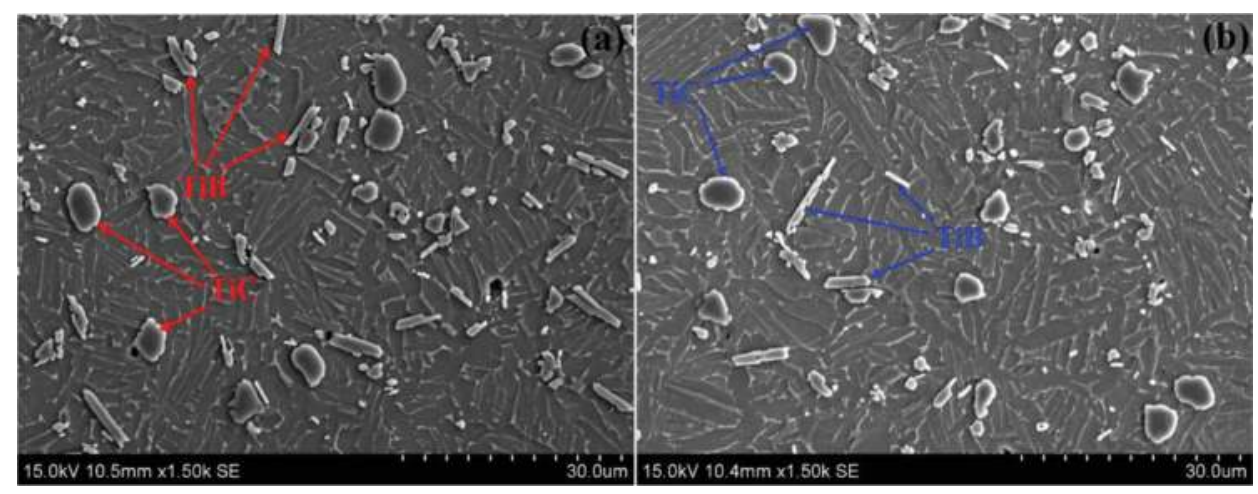

Figure 11. SEM images of reinforcements in (TiB+TiC)/Ti-Al-4V after etching on surface with different percentage; (a) $8 \%(\mathrm{TiB}+\mathrm{TiC})[36] ;$ (b) $5 \%$ (TiB+TiC) [43].

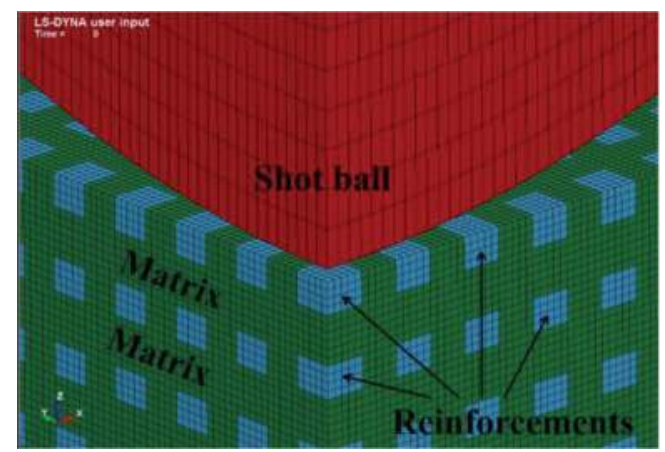

Figure 12. 3D SP model for inhomogeneous materials [36].

blue parts with disjunction distribution represent the reinforcements $\mathrm{TiB}$ and $\mathrm{TiC}$, and the red and $1 / 4$ spherical object is the shot ball. Because the mechanic parameters of these two reinforcements are similar, one kind of mesh is used in this model to simplify the calculation. Moreover, the whole mesh number reaches 320,000 . In addition, a combination of two kinds of materials is built, one is the matrix Ti-6 Al- $4 \mathrm{~V}$, and the other is the average parameters of $\mathrm{TiB}$ and $\mathrm{TiC}$. Wherein the relatively large area of plastic deformation, actually the directly impact area, the quite fine mesh is introduced. In this inhomogeneous model, the volume percentage of reinforcement is set as $8 \%$ based on the microstructure of material. The $1 / 4$ symmetry model is set up and the nonreflecting boundary conditions on flank of model are applied. The symmetric boundary conditions are also applied on the symmetry plane in order to avoid the effect of stress wave.

\subsection{Residual stress distribution}

The residual stress distribution $\left(\sigma_{x x}\right)$ of plastic deformation area is shown in Figure $\mathbf{1 3}$ after SP. In the plastic deformation zone, there are both CRS and tensile stresses, the max CRS is 


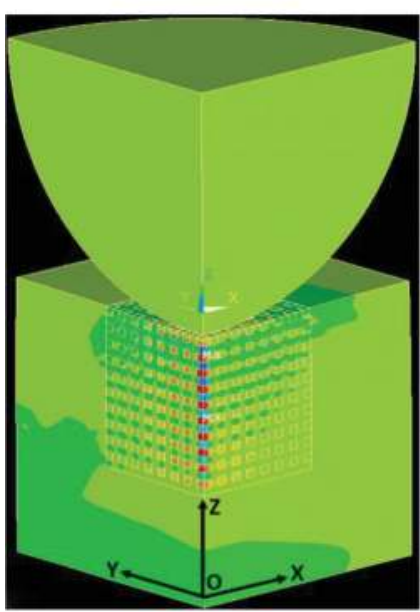

(a)

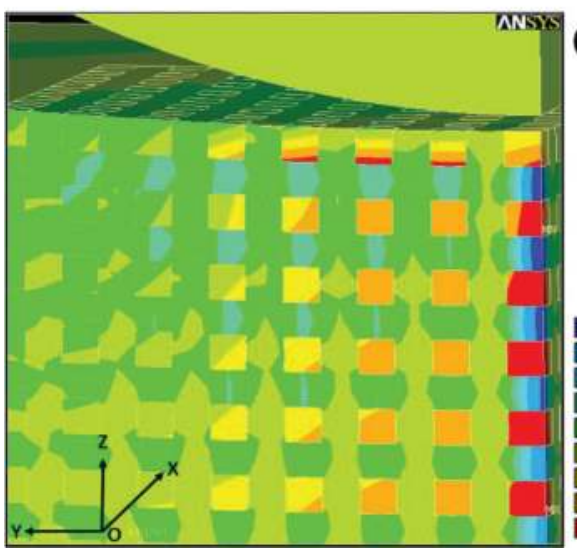

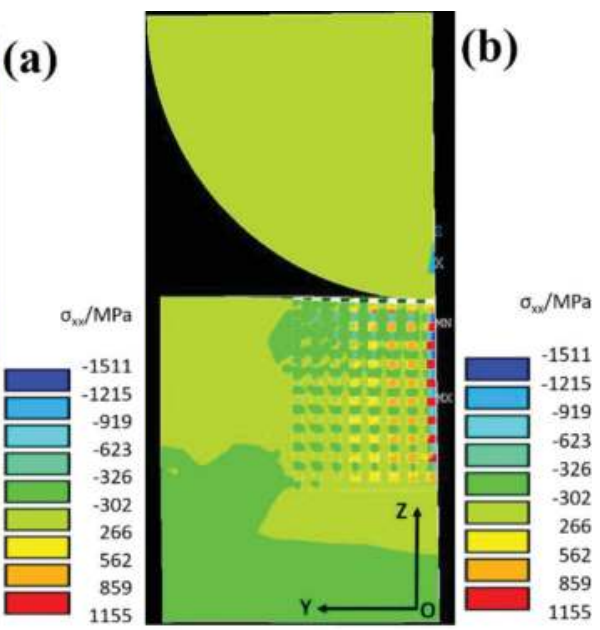

(b)

\section{(c)}

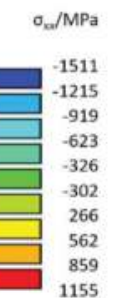

Figure 13. Residual stress distribution in depth simulated from inhomogeneous SP model ( $\sigma_{x x}$ direction); (a) 3D result; (b) $2 \mathrm{D}$ result; (c) magnification of $2 \mathrm{D}$ result.

$-1511 \mathrm{MPa}$ and the max tensile residual stress is +1155 MPa. Moreover, the CRS exist in the matrix, but there are tensile residual stresses in the reinforcements, which reveal that the reinforcements withstand the tensile stresses, and this stress distribution indicates the higher yield strength of reinforcements. The stress distribution indicates the effect of reinforcements, keeping the adverse tensile stresses in reinforcements and retarding the damage to matrix. The different residual stress distributions between the matrix and reinforcements are resulted from the different mechanical properties, consisting with the desired results after SP treatments.

The simulation results of residual stress field of SP $\left(\sigma_{x x}\right)$ on the whole surface are shown in Figure 14. The similar stress distribution as Figure $\mathbf{1 3}$ has been shown, in and around the reinforcement. Tensile residual stress appears and the stress concentration exists, but between the reinforcements, there are CRS and the distribution of CRS is uniform below the subsurface (in 


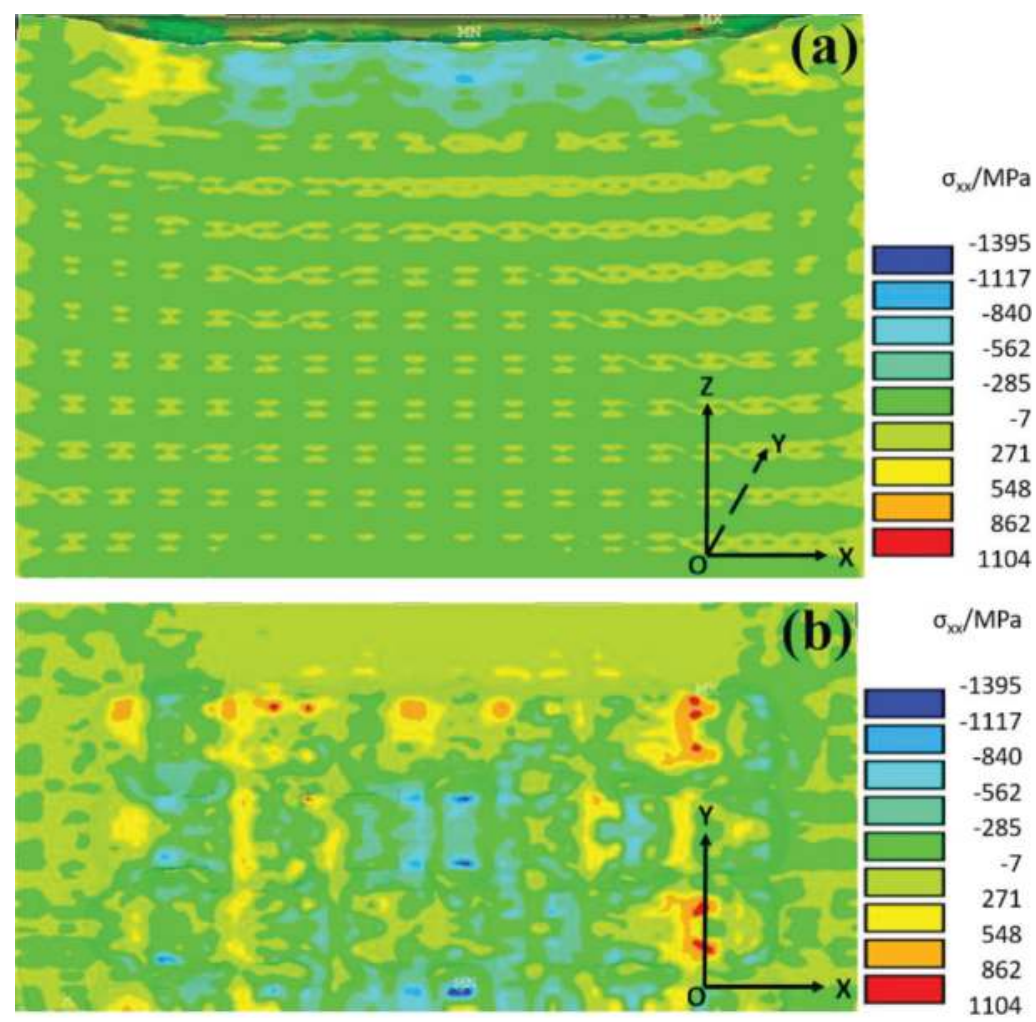

Figure 14. Simulation results of residual stress field of SP $\left(\sigma_{x x}\right)$ on the whole surface; (a) 3D result; (b) 2D result of surface.

Figure 14(a)). In addition, it is obvious that the max CRS appears in the subsurface, and after SP treatment of $200 \%$ coverage rate, the deformation of surface layer can be observed from the cross section (in Figure 14(a)) and the surface (in Figure 14(b)). Comparing with the residual stress distribution on the surface of homogeneous material in Figure 5, the stress distribution on surface of composite in Figure 14(b) is not uniform because the influence of reinforcements. The value of max CRS and tensile residual stress in Figure 14(b) are increased a little comparing the results in Figure 5(b). The detailed discussion will be carried out in the following section.

\subsection{Influence of reinforcements on residual stress distribution}

The stress difference between the reinforcement and matrix is mainly due to the large mechanical differences between them. During the SP process, the matrix material and the reinforcement are deformed by the pressure caused by the impact of shot balls. The matrix material is deformed easily due to the small Young's modulus and yield strength. But the Young's modulus of the reinforcement is very large. The reinforcement in the surface undergoes bending under the vertical impact of shot balls, the reinforcement in the deeper area of plastic deformation zone is mainly deformed elastically. Some of the surface reinforcements are deformed in the plastic and result in high tensile residual stress (in Figure 14(a)). After SP, 
there is still high compressive stress in the plastic deformation zone even though the elastic recovery occurs. Meanwhile, the elastic recovery of matrix is limited by the reinforcement, which also makes the CRS in matrix further improved.

During SP process, the matrix material in the composite undergoes the severe plastic deformation and the compressive stress is introduced. The tensile stress in whisker reinforcements is produced with a symmetrical distribution due to the bending deformation. In the top region where the whisker is strengthened, also the compressive stress is produced, but it is significantly less than the stress between the whisker reinforcements. After SP, the material will spontaneously show the elastic recovery and both the compressive and tensile stress are reduced. While the elastic recovery is completed, the compressive stress region is obtained in the matrix between the whisker reinforcements and the tensile stress is retained in the reinforcements (in Figure 14). Since the tensile stresses in reinforcement are much lower than the strength of reinforcement, it is reasonable to believe that these tensile stresses have no detrimental influences on the fatigue properties of shot peened composites. In order to verify the simulated results obtained by $3 \mathrm{D}$ finite element dynamic analysis, the experimental investigation on residual stress distribution of Ti-6Al-4V and 8\% (TiB+TiC)/Ti-6Al-4V after SP are carried out via XRD method.

\section{Experimental validation on residual stress distribution}

\subsection{Experimental process}

SP treatment was performed using an air blast machine (Carthing Machinery Company, Shanghai, China). The SP intensities were: $0.15,0.30$, and $0.45 \mathrm{mmA}$. The distance between nozzle and samples was $100 \mathrm{~mm}$ and the diameter of peening nozzle was $15 \mathrm{~mm}$. The shot media was cast steel ball with hardness of $610 \mathrm{HV}$ and average radius of $0.3 \mathrm{~mm}$. In order to obtain the uniform stress field on surface, the coverage rate of SP process was $200 \%$. Residual stresses were measured by X-ray stress analyzer (LXRD, Proto, Canada) with $\mathrm{Cu}-\mathrm{Ka}$ radiation under $30 \mathrm{kV} / 25 \mathrm{~mA}$ and Ni filter. The diffraction peak of Ti (213) was detected in the measurements and then the residual stresses were determined according to the $\sin ^{2} \psi$ method [44] and the range of tilting angles was $0-45^{\circ}$. The schematic figure of residual stress measurement coordinate was shown in Figure 15(a) and the photo of residual stress measurement using X-ray stress analyzer was presented in Figure 15(b). For obtaining the stress distribution along the depth, the thin top surface layer was removed one by one via chemical etch method with a solution of distilled water, nitric acid, and hydrofluoric acid in proportion of 31:12:7.

\subsection{Residual stress distribution of Ti-6Al-4V}

The CRS distribution of Ti-6Al-4V under three different SP intensities is shown in Figure 16(a). The residual stresses are compressive stresses and the values increase to max and then decrease, close to the simulated results by the homogeneous SP model. When the SP intensity increases from 0.15 to $0.45 \mathrm{mmA}$, the depths of max CRS are located at 50, 50, and $75 \mu \mathrm{m}$, corresponding to the intensity of $0.15,0.30$, and $0.45 \mathrm{mmA}$, respectively. The surface deformation layers are 275,325 , and $400 \mu \mathrm{m}$ depth, which show that the deformation layer depth increases gradually with increasing SP intensity. In addition, with the increase of SP intensity, the CRS of surface is enhanced from 


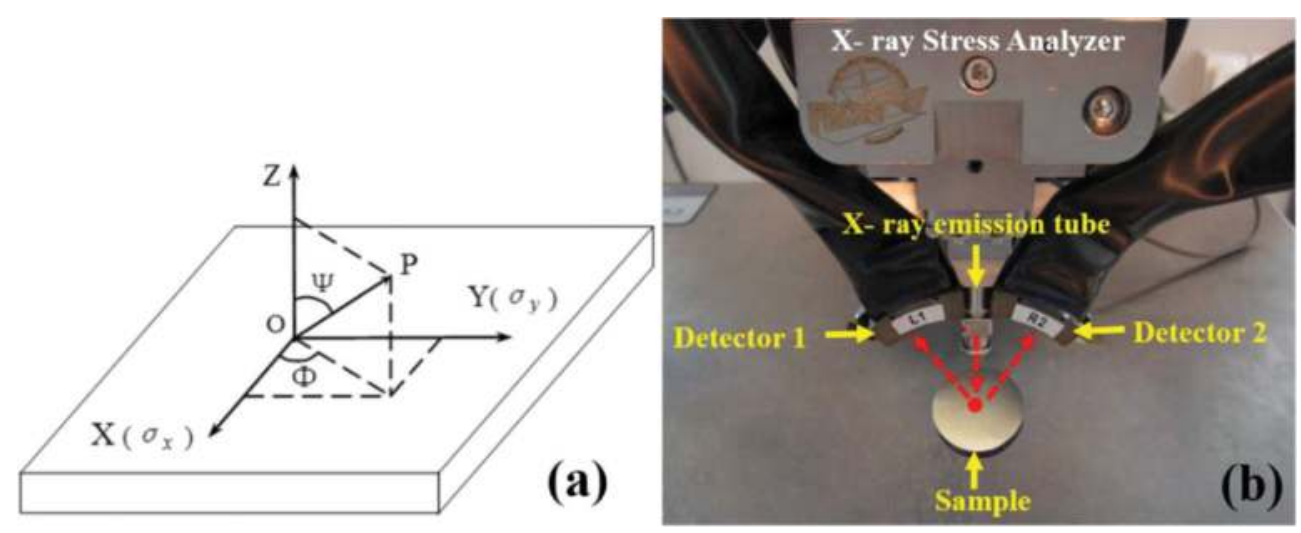

Figure 15. (a) Schematic figure of residual stress measurement coordinate; (b) photo of the residual stress measurement using X-ray stress analyzer.
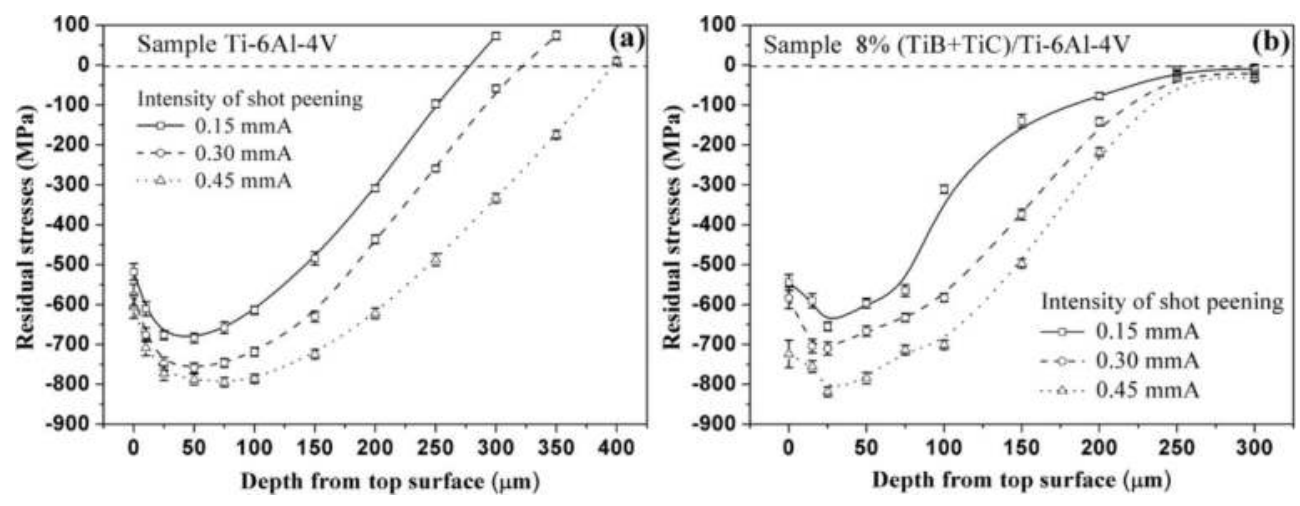

Figure 16. Depth distribution of CRS on the matrix and composite under three different SP intensities [36], (a) Ti-6Al-4V; (b) $8 \%(\mathrm{TiB}+\mathrm{TiC}) / \mathrm{Ti}-6 \mathrm{Al}-4 \mathrm{~V}$.

-517 to $-605 \mathrm{MPa}$, which is improved by $17 \%$. The max CRS varies from -684 to $-794 \mathrm{MPa}$ and the increase rate is about $16 \%$. It is mainly due to the improved shot velocity after increasing SP intensity, which can cause more severe plastic deformation on surface, the deeper surface deformation layer and the larger CRS. Comparing the results by simulation and experiment, it reveals that the variation trends of residual stress by simulation are similar with the results from experiment.

\subsection{Residual stress distribution of $8 \%(\mathrm{TiB}+\mathrm{TiC}) / \mathrm{Ti}-6 \mathrm{Al}-4 \mathrm{~V}$}

Figure 16(b) shows the experimental results of residual stress distribution on the composite $8 \%(\mathrm{TiB}+\mathrm{TiC}) / \mathrm{Ti}-6 \mathrm{Al}-4 \mathrm{~V}$. From the figure, the depths of surface deformation layer are 200, 250, and $300 \mu \mathrm{m}$ corresponding to $0.15,0.30$, and $0.45 \mathrm{mmA}$, which are shallower than the matrix's. The difference is resulted from the existence of reinforcements' resistance to the deformation of surface. Moreover, SP intensity has direct relation to the shot velocity. The larger impact velocity, the higher impact kinetic energy, and the depths of surface deformation layer are deeper. 
At the same depth, the higher of SP intensity, the values of CRS are bigger. These variation trends of residual stresses are similar to Figure 16(a), and the depths of max CRS are located at $25 \mu \mathrm{m}$, which are shallower than the matrix's under the same SP intensity. The CRS of surface is enhanced from -545 to $-724 \mathrm{MPa}$ and the max CRS varies from -655 to $-819 \mathrm{MPa}$. Contrasting the results from experiment and simulation, the ranges of residual stress measured via experiments are good agreement with the simulated results by 3D finite element dynamic analysis shown in Figure 13. The difference between simulation and experiment are inevitable, because the irradiation area of X-ray is larger than the dimension of reinforcement, and the tested residual stresses show the average values of the matrix and reinforcements. Based on all results, analysis and discussion, 3D finite element dynamic analysis is an effective method to simulate the residual stress distribution of metal matrix composite after SP treatment, especially to obtain the residual stress distribution in and around the reinforcements in the composite.

\section{Conclusions}

In order to study the effect of various parameters on the residual stress distribution after SP, LS/DYNA analysis module in ANSYS is utilized to establish the finite element model for Ti-6Al-4V and (TiB+TiC)/Ti-6Al-4V, and both 3D homogeneous and inhomogeneous models are set up. The influence of coverage rate, shot radius, and shot velocity on residual stress distribution is studied using the multi-layer shot balls to simulate the actual SP process. The main results are concluded as the following:

1. The influence of different coverage rates on residual stress distribution is investigated. With increasing coverage rate, the number of craters on the surface is increased obviously, and the uniformity of surface residual stresses is improved a lot. Comparing the results under coverage rate of 200 and $300 \%$, the increment of surface residual stresses are not obvious, since the surface of almost all covered by craters and the stress field reaches saturation.

2. The influence of cast steel shot balls with different radius on the residual stress distribution is simulated when the shot velocity is $100 \mathrm{~m} / \mathrm{s}$. The CRS induced by smaller shot balls is higher, but the depth of residual stress layer is smaller and decreases rapidly. While increasing radius, the surface and max CRS are smaller, while the depth of residual stress layer decreases slowly.

3. The simulation results of different shot velocities show that the higher CRS and the deeper residual stress layer can be obtained under higher velocity. At $100 \mathrm{~m} / \mathrm{s}$, the max depth of CRS reaches $600 \mu \mathrm{m}$ with $r=0.6 \mathrm{~mm}$ and coverage $=200 \%$. The surface residual stress is less affected by shot velocity, while the radius of shot balls is $0.3 \mathrm{~mm}$ and the surface residual stress under two kinds of velocities is around -100 to $-200 \mathrm{MPa}$.

4. The residual stress distribution in the plastic deformation zone, and in and around the reinforcements are obtained. Due to the different mechanic properties between the reinforcement and matrix, the elastic deformation of the reinforcement is mainly caused by SP, and a large tensile residual stress is formed in the body of reinforcement. Meanwhile, the plastic deformation of the matrix occurs and CRS are formed. After the elastic recovery, there is still high CRS remained in the matrix. 
5. The results obtained from the inhomogeneous SP model reveal that the compressive and tensile residual stresses are introduced in (TiB+TiC)/Ti-6Al-4V. The max CRS and tensile residual stress are -1511 and $+1155 \mathrm{MPa}$, respectively. CRS appear in matrix, but the tensile residual stresses gets generated in the reinforcements, which reveals the higher yield strength of reinforcements. This stress distribution indicates the effect of reinforcements, keeping the adverse tensile stresses in reinforcements and retarding the damage to matrix.

6. The experimental results from XRD method are shown that the surface CRS increased from -545 to $-724 \mathrm{MPa}$ and the max CRS varies from -655 to $-819 \mathrm{MPa}$. The ranges of residual stress distribution in experiments are in good agreement with the simulated results by 3D finite element dynamic analysis.

From all results and discussion, using 3D finite element dynamic analysis to simulate the residual stress distribution of titanium matrix composite is reasonable, especially for the stress distribution in and around the reinforcements.

\section{Acknowledgements}

This work is supported by the projects of "Chu Tian Scholar" of Hubei Province in China (CTXZ2017-05), The 111 Project (B17034), National Natural Science Foundation of China (No. 51302168, No. 51405356 and No. 51502142), 973 Program (No. 2014CB046701) and Shanghai Pujiang Program (No. 15PJD017). The financial support of the Jiangsu Higher Education Institutions of China (No. 15KJB430021) and the Startup Foundation for Introducing Talent of NUIST (No. 2014r036) are gratefully appreciated. The financial support of Research Fund for the Doctoral Program of Higher Education of China (No. 20130143120015), Medical Engineering Cross Research Foundation of Shanghai Jiao Tong University (No. YG2014MS02), Shanghai Jiao Tong University Chenxing Program (No. 15X100080069) are appreciated.

\section{Author details}

Lechun Xie ${ }^{1,2 *}$, Zhou Wang ${ }^{1}$, Chengxi Wang ${ }^{3}$, Yan Wen ${ }^{1}$, Liqiang Wang ${ }^{3 *}$, Chuanhai Jiang ${ }^{3}$, Weijie $\mathrm{Lu}^{3}$, Lai-Chang Zhang ${ }^{4}$ and Lin Hua ${ }^{1}$

*Address all correspondence to: lechunxie@yahoo.com and wang_liqiang@sjtu.edu.cn

1 Hubei Key Laboratory of Advanced Technology for Automotive Components, School of Automotive Engineering, Wuhan University of Technology, Wuhan, Hubei Province, P.R. China

2 Institute for Frontier Materials, Deakin University, Geelong, VIC, Australia

3 State Key Laboratory of Metal Matrix Composites, School of Materials Science and Engineering, Shanghai Jiao Tong University, Shanghai, P.R. China

4 School of Engineering, Edith Cowan University, Perth, WA, Australia 


\section{References}

[1] Bruno G, Fernández R, Gonzalez-Doncel G. Relaxation of the residual stress in 6061Al15 vol.\% SiC w composites by isothermal annealing. Materials Science and Engineering A. 2004;382:188-197

[2] Schulze V. Characteristics of surface layers produced by shot peening. In: Proceeding of the Eighth International Conference on Shot Peening ICSP-8 in Garmisch-Partenkirchen DGM, Citeseer. 2002. pp. 145-160

[3] Kim K-H, Kim Y-C, Jeon E-C, Kwon D. Evaluation of indentation tensile properties of Ti alloys by considering plastic constraint effect. Materials Science and Engineering A. 2011;528:5259-5263

[4] Benedetti M, Fontanari V, Monelli B. Numerical simulation of residual stress relaxation in shot peened high-strength aluminum alloys under reverse bending fatigue. Journal of Engineering Materials and Technology. 2010;132:011012

[5] Kim T, Lee JH, Lee H, Cheong S-k. An area-average approach to peening residual stress under multi-impacts using a three-dimensional symmetry-cell finite element model with plastic shots. Materials \& Design. 2010;31:50-59

[6] Prasannavenkatesan R, Zhang J, McDowell DL, Olson GB, Jou H-J. 3D modeling of subsurface fatigue crack nucleation potency of primary inclusions in heat treated and shot peened martensitic gear steels. International Journal of Fatigue. 2009;31:1176-1189

[7] Guagliano M. Relating Almen intensity to residual stresses induced by shot peening: A numerical approach. Journal of Materials Processing Technology. 2001;110:277-286

[8] Rouhaud E, Ouakka A, Ould C, Chaboche J, Francois M. Finite elements model of shot peening, effects of constitutive laws of the material, Proceedings ICSP-9, Paris, France. 2005

[9] Ould C, Rouhaud E, François M, Chaboche JL. A kinematic hardening finite elements model to evaluate residual stresses in shot-peened parts, local measurements by X-ray diffraction. In: Mater. Sci. Forum Trans Tech Publ. 2006. pp. 161-166

[10] Baragetti S, Guagliano M, Vergani L. A numerical procedure for shot peening optimisation by means of non-dimensional factors. International Journal of Materials and Product Technology. 2000;15:91-103

[11] Boyce B, Chen X, Hutchinson J, Ritchie R. The residual stress state due to a spherical hard-body impact. Mechanics of Materials. 2001;33:441-454

[12] Evans R. Shot peening process: Modelling, verification, and optimisation. Materials Science and Technology. 2002;18:831-839

[13] Levers A. A. Prior, finite element analysis of shot peening. Journal of Materials Processing Technology. 1998;80:304-308 
[14] Meguid S, Shagal G, Stranart J, Daly J. Three-dimensional dynamic finite element analysis of shot-peening induced residual stresses. Finite Elements in Analysis and Design. 1999;31:179-191

[15] Majzoobi G, Azizi R, Nia AA. A three-dimensional simulation of shot peening process using multiple shot impacts. Journal of Materials Processing Technology. 2005; 164:1226-1234

[16] Frija M, Hassine T, Fathallah R, Bouraoui C, Dogui A, de Génie Mécanique L. Finite element modelling of shot peening process: Prediction of the compressive residual stresses, the plastic deformations and the surface integrity. Materials Science and Engineering A. 2006;426:173-180

[17] Wang T, Platts M, Wu J. The optimisation of shot peen forming processes. Journal of Materials Processing Technology. 2008;206:78-82

[18] Hong T, Ooi J, Shaw B. A numerical simulation to relate the shot peening parameters to the induced residual stresses. Engineering Failure Analysis. 2008;15:1097-1110

[19] Kim T, Lee H, Jung S, Lee JH. A 3D FE model with plastic shot for evaluation of equibiaxial peening residual stress due to multi-impacts. Surface and Coating Technology. 2012;206:3125-3136

[20] Meo M, Vignjevic R. Finite element analysis of residual stress induced by shot peening process. Advances in Engineering Software. 2003;34:569-575

[21] Böhm HJ, Han W. Comparisons between three-dimensional and two-dimensional multiparticle unit cell models for particle reinforced metal matrix composites. Modelling and Simulation in Materials Science and Engineering. 2001;9:47

[22] Böhm HJ, Eckschlager A, Han W. Multi-inclusion unit cell models for metal matrix composites with randomly oriented discontinuous reinforcements. Computational Materials Science. 2002;25:42-53

[23] Han W, Eckschlager A, Böhm HJ. The effects of three-dimensional multi-particle arrangements on the mechanical behavior and damage initiation of particle-reinforced MMCs. Composites Science and Technology. 2001;61:1581-1590

[24] Duschlbauer D, BÖhm HJ, Pettermann HE. Computational simulation of composites reinforced by planar random fibers: Homogenization and localization by unit cell and mean field approaches. Journal of Composite Materials. 2006;40:2217-2234

[25] Borbely A, Biermann H, Hartmann O. FE investigation of the effect of particle distribution on the uniaxial stress-strain behaviour of particulate reinforced metal-matrix composites. Materials Science and Engineering A. 2001;313:34-45

[26] Su X-fC, Hao-ran, Wang, Li-min, Relations of the mesoscopic damage mechanisms with the macroscopic properties of metal matrix composites. Acta Metallurgica Sinica(English letters). 1999;16:88-93 
[27] Kuruvilla A, Prasad K, Bhanuprasad V, Mahajan Y. Microstructure-property correlation in AlTiB2 (XD) composites. ScMM. 1990;24:873-878

[28] Ranganath S. A review on particulate-reinforced titanium matrix composites. Journal of Materials Science. 1997;32:1-16

[29] Zhang L-C, Attar H. Selective laser melting of titanium alloys and titanium matrix composites for biomedical applications: A review. Advanced Engineering Materials. 2016; 18:463-475

[30] Xie L, Jiang C, Lu W, Chen Y, Huang J. Effect of stress peening on surface layer characteristics of $(\mathrm{TiB}+\mathrm{TiC}) / \mathrm{Ti}-6 \mathrm{Al}-4 \mathrm{~V}$ composite. Materials \& Design. 2012;33:64-68

[31] Xie L, Jiang C, Lu W, Zhan K, Chen Y. Investigation on the residual stress and microstructure of $(\mathrm{TiB}+\mathrm{TiC}) / \mathrm{Ti}-6 \mathrm{Al}-4 \mathrm{~V}$ composite after shot peening. Materials Science and Engineering A. 2011;528:3423-3427

[32] Xie L, Jiang C, Lu W. The influence of shot peening on the surface properties of (TiB+ $\mathrm{TiC}) / \mathrm{Ti}-6 \mathrm{Al}-4 \mathrm{~V}$. Applied Surface Science. 2013;280:981-988

[33] Xie L, Jiang C, Lu W, Feng Q, Wu X. Investigation on the surface layer characteristics of shot peened titanium matrix composite utilizing X-ray diffraction. Surface and Coating Technology. 2011;206:511-516

[34] ANSYS. Ansys Ls-Dyna User's Guide. ANSYS, Inc: Canonsburg; 2008

[35] ANSYS, Release 11.0: Element Reference., in, ANSYS Inc, 2007

[36] Xie L, Wang C, Wang L, Wang Z, Jiang C, Lu W, Ji V. Numerical analysis and experimental validation on residual stress distribution of titanium matrix composite after shot peening treatment. Mechanics of Materials. 2016;99:2-8

[37] Dowling NE. Mechanical Behavior of Materials: Engineering Methods for Deformation, Fracture, and Fatigue. Pearson; 2012

[38] Symonds PS. Viscoplastic behavior in response of structures to dynamic loading. In: Huffington NJ, editor. Behavior of Materials under Dynamic Loading. New York: American Society of Mechanical Engineers; 1965. pp. 106-124

[39] Jones N. Structural aspects of ship collisions. In: Wierzbicki NJ, editor. Structural Crashworthiness. Butterworth; 1983. pp. 308-337

[40] Aljawi A. Plastic deformation of thin plates subjected to quasi-static and dynamic loadings. The Journal of Engineering Research [TJER]. 2004;1:59-74

[41] Fang B. Controlled Shot Peening and Residual Stress Theory (in Chinese). Shandong Science and Technology Press; 1991

[42] Klemenz M. Anwendung der Simulation der Randschichtausbildung beim Kugelstrahlen auf die Abschätzung der Schwingfestigkeit gekerbter Bauteile, in. Shaker, Aachen: Universität Karlsruhe; 2009 
[43] Xie L, Feng Q, Wen Y, Wang L, Jiang C, Lu W. Surface microstructure characterization on shot peened $(\mathrm{TiB}+\mathrm{TiC}) / \mathrm{Ti}-6 \mathrm{Al}-4 \mathrm{~V}$ by Rietveld whole pattern fitting method. Journal of Materials Research. 2016;31:2291-2301

[44] Withers P, Bhadeshia H. Residual stress. Part 1-measurement techniques. Materials Science and Technology. 2001;17:355-365 